\title{
A new species of Hysterothylacium (Nematoda: Anisakidae) from the giant mottled eel Anguilla marmorata in South Africa
}

\author{
F. MORAVEC ${ }^{1 *}$, H. TARASCHEWSKI ${ }^{2}$, D. APPELHOFF ${ }^{2}$, O. WEYL $^{3}$
}

\begin{abstract}
${ }^{1}$ Institute of Parasitology, Biological Centre, Academy of Sciences of the Czech Republic, Branišovská 31,37005
České Budějovice, Czech Republic, E- mail: moravec@paru.cas.cz; ${ }^{2}$ Abteilung Ökologie und Parasitologie, Zoologisches Institut der Universität Karlsruhe (TH), Kaiserstrasse 12, 76128 Karlsruhe, Germany; ${ }^{3}$ South African Institute for Aquatic Biodiversity, Private Bag 1015, Grahamstown, South Africa
\end{abstract}

\begin{abstract}
Summary
A new species of ascaridoid nematode, Hysterothylacium anguillae sp. n. (family Anisakidae), is described based on specimens recovered from the stomach and intestine of the giant mottled eel Anguilla marmorata Quoy et Gaimard from the Mngazi River, South Africa, collected in MarchApril 2011. It is characterized mainly by poorly developed lateral alae, a very short intestinal caecum and a long ventricular appendix, spicules $1.11-2.14 \mathrm{~mm}$ long (representing $5.2-5.8 \%$ of body length), number of caudal papillae $(19-21$ pairs of preanals, 2 adanals and 5 postanals), presence of a median precloacal papilla (= ventromedian organ), tail tips of both sexes covered by minute spines, and by the shape and structure of lips. This is the first nominal species of Hysterothylacium described from an African freshwater fish and the second species of this genus reported from freshwater eels of the family Anguillidae. The following Indian congeneric species are considered species inquirendae: Hysterothalacium aetobathum Lakshmi, 2005, H. carutti Lakshmi, Rao et Shyamasundari, 1993, H. channai Lakshmi, 1995, H. fossillii Lakshmi, 1996, H. japonicum Rajialakshmi, 1996, H. kiranii Lakshmi, 1993, H. longicaecum Lakshmi, Rao et Shyamansundari, 1993, H. narayensis Lakshmi, 1997, H. nellorensis Lakshmi, 1996, H. neocornutum Rajialakshmi, Rao et Shyamasundari, 1992 and H. punctati Lakshmi, 1995. Of them, H. japonicum and H. neocornutum are transferred to Iheringascaris Pereira, 1935 as I. japonica (Rajialakshmi, 1996) comb. n. and I. neocornuta (Rajialakshmi, Rao et Shyamasundari, 1992) comb. n.
\end{abstract}

Keywords: parasitic nematode; Hysterothylacium; fish; Anguilla; South Africa

\section{Introduction}

During recent studies on parasites of eels (Anguilla spp.) in the Mngazi River, South Africa, adults and fourth-stage larvae of an ascaridoid nematode of the genus Hysterothylacium Ward et Magath, 1917 were recovered from the stomach and intestine of the giant mottled eel Anguilla marmorata Quoy et Gaimard. Their closer examination revealed that they represent a new species, which is described herein. To date, the only record of a representative of Hysterothylacium in freshwater fish in Africa is that of Obiekezie et al. (1988), who reported an unidentified larva of Hysterothylacium from the body cavity of the bagrid catfish Chrysichthys nigrodigitatus (Lacèpéde) from the Cross River Estuary, Nigeria (see also Khalil \& Polling, 1997).

Anguilla marmorata is a tropical fish with a maximum body length of $200 \mathrm{~cm}$ (female) and $70 \mathrm{~cm}$ (male), maximum weight $20.5 \mathrm{~kg}$, whose adults occur in fresh waters. The species is distributed in the Indo-Pacific from East Africa to French Polynesia, north to Japan, and in Africa in inland Mozambique and lower Zambezi River (Froese \& Pauly, 2011).

\section{Materials and methods}

Fish were collected from the Mngazi River ( $31^{\circ} 37.044^{\prime}$ S, $\left.29^{\circ} 25.715^{\prime} \mathrm{E}\right)$ during the southern hemisphere summer ( 30 March - 4 April), using double ended fyke nets. The nematodes for morphological studies were fixed in $70 \%$ ethanol. For light microscopical examination (LM), they were cleared with glycerine. Drawings were made with the aid of a Zeiss microscope drawing attachment. Specimens used for scanning electron microscopy (SEM) were postfixed in $1 \%$ osmium tetroxide, dehydrated through a graded acetone series, critical point dried and sputtercoated with gold; they were examined using a JEOL JSM$7401 \mathrm{~F}$ scanning electron microscope at an accelerating voltage of $4 \mathrm{kV}$ GB low. All measurements are in micrometres unless otherwise stated. Fish names follow FishBase (Froese \& Pauly, 2011). 


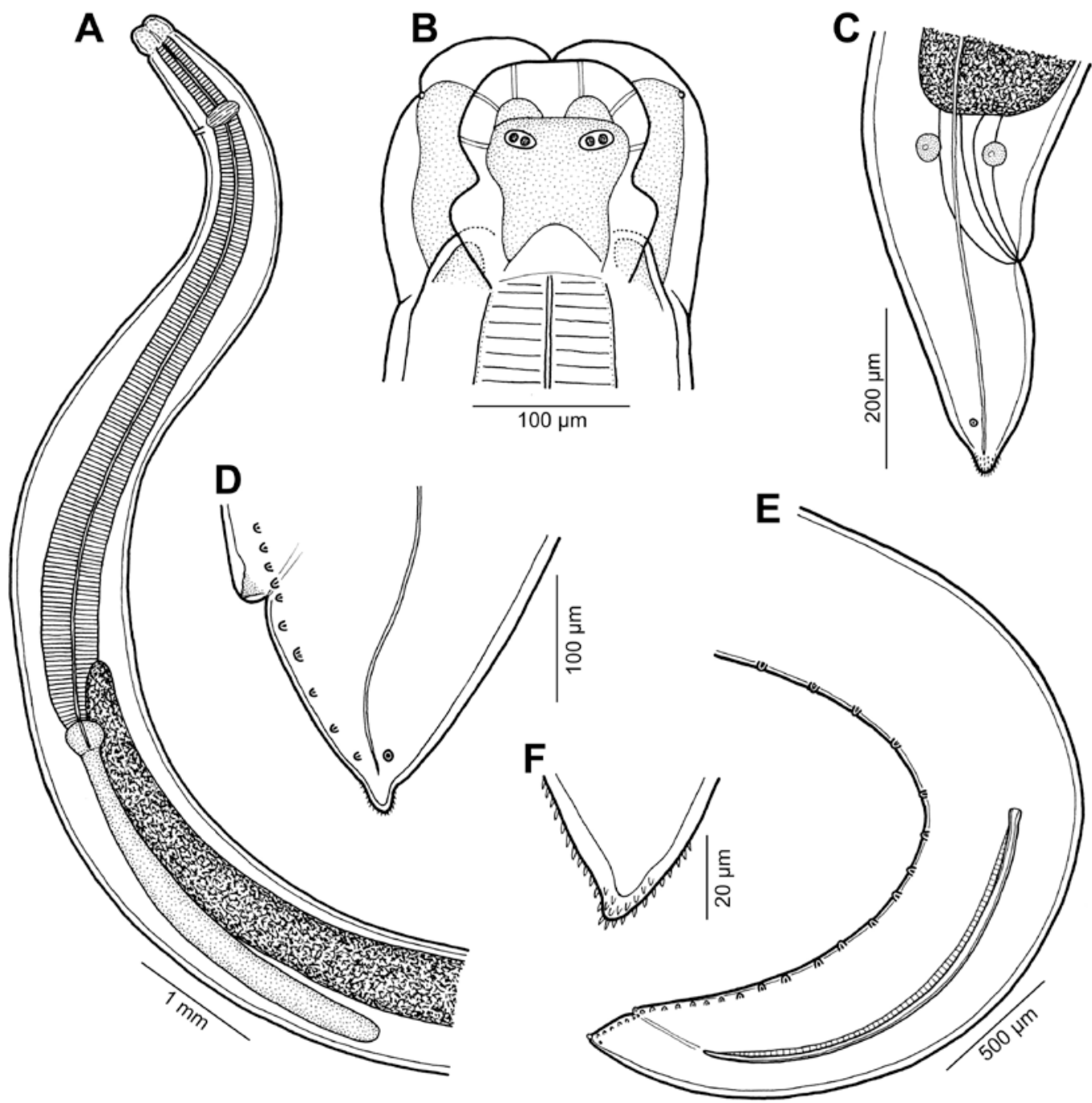

Fig. 1. Hysterothylacium anguillae sp. n. A) Anterior end of male, lateral view; B) Cephalic end of male, dorsal view; C) Tail of young female, lateral view; D) Tail of male, lateral view; E) Posterior end of male, lateral view; F) Tail tip of female, lateral view

\section{Description}

Hysterothylacium anguillae sp. n. (Figs. 1-3)

\section{Description}

General: Medium-sized nematodes with transversely striated cuticle, whitish in ethanol. Maximum width near middle of body. Lips almost equal in size (dorsal lip slightly smaller than ventrolateral lips), longer than wide, with relatively broad bases, their lateral flanges widest just posterior to middle of lips; pulp with two anteriorly protruding lobes. Dorsal lip with two subdorsal double papillae; each subventral lip with one double subventral papilla, one small single papilla and amphid situated laterally (Figs $1 \mathrm{~B}, 2 \mathrm{~A}-\mathrm{D})$. Interlabia low, less than $1 / 3$ length of lips (Figs 1B, 2A, D). Lateral alae poorly developed, almost indistinct, starting at about level of mid-length of oesophagus, and in both sexes extending posteriorly as cordons to tail tip (Fig. 3C, F, G, H). Deirids indistinct. Oesophagus long, slightly broader posteriorly than anteriorly. Nerve ring encircling oesophagus approximately at border of first and second eighths of its length. Ventriculus small, almost spherical; ventricular appendix long and narrow. Intestinal caecum markedly short. Excretory pore just posterior to nerve ring (Fig. 1A). Tail of both sexes conical, tip with numerous cuticular spines.

Male (3 specimens; measurements of holotype in parentheses): Length of body $19.14-40.91$ (19.14) mm, maximum width 530 - 925 (612). Lips 163 - 218 (163) long. Length of oesophagus $2.82-5.10(2.82) \mathrm{mm}$, representing $12-15$ (15) \% of body length; maximum width $231-367$ (231). Nerve ring and excretory pore $571-843$ (571) and $575-$ 846 (575), respectively, from anterior extremity. Ventriculus $136-163 \times 190-245$ (136 x 190); ventricular appendix $1.11-2.83$ (1.11) mm long, maximum width 82204 (82). Intestinal caecum 367 - 544 (367) long, maximum width $136-204$ (136). Caecum to ventricular appendix length ratio 1:3.0 - 5.2 (1:3.0). Posterior end of body 


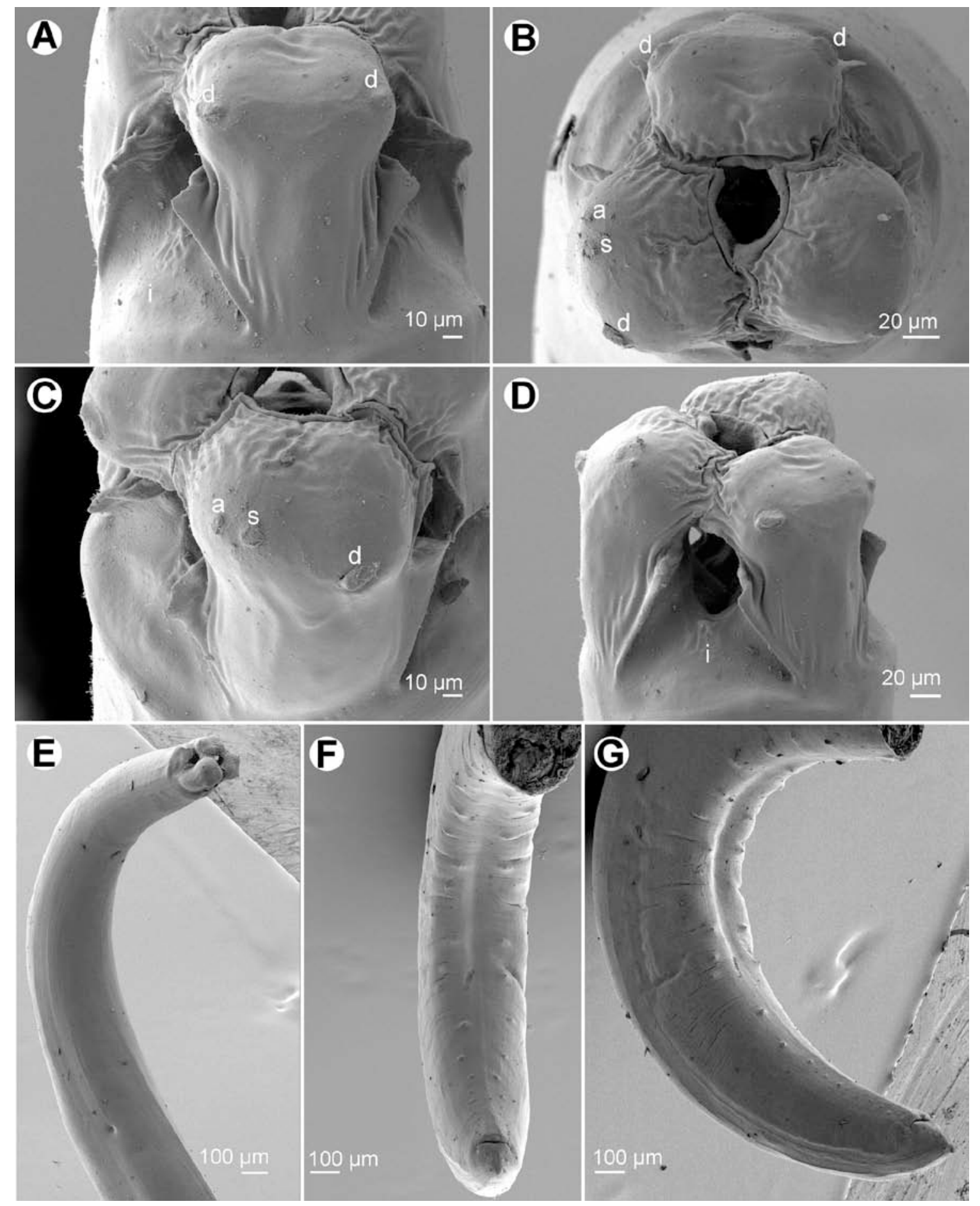

Fig. 2. Hysterothylacium anguillae sp. n., scanning electron micrographs of male. A) Dorsal lip; B) Cephalic end, apical view; C) Subventral lip; D) Cephalic end, sublateral view; E) Anterior end of body, lateral view; F,G) Ventral and lateral views. a - amphid, d - double labial papilla, i interlabium, s- single labial papilla.

curved ventrally. Spicules equal, alate, $1.11-2.14$ (1.11) mm long, representing $5.2-5.8$ (5.8) \% of body length. Total of $26-28$ (26) pairs of small subventral papillae present, 19 - 21 (19) being preanals, 2 (2) adanals, and 5 (5) postanals; papillae of several posteriormost preanal pairs and of postanal pairs very small; papillae of second postanal pair doubled (Figs 1D, E, 2F, G, 3A, B, D, F). One median papilla or ventromedian organ located on anterior cloacal lip present, being surrouded by roughly granulated cuticle (Figs. 1D, 3D - F). Tail conical, $163-$ 190 (163) long; tip 18 - 30 (18) long, bearing numerous spines (Figs 1D, 3D, F, G). 

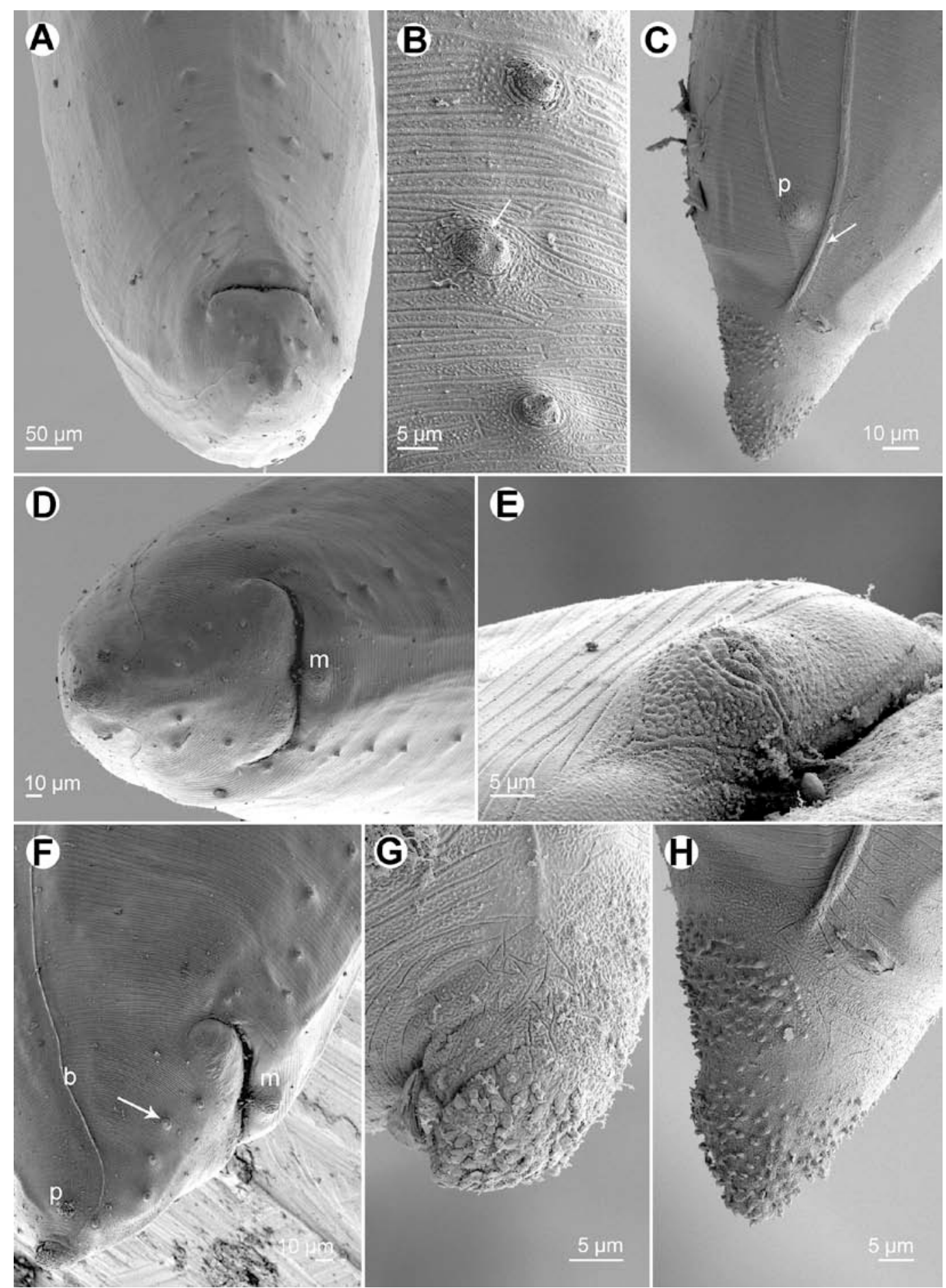

Fig. 3. Hysterothylacium anguillae sp. n., scanning electron micrographs. A) Posterior end of male, ventral view; B) Postanal papillae (arrow indicates double papilla); C) Posterior end of female tail, lateral view (arrow indicates lateral ala); D) Tail of male, ventral view; E) Ventromedian organ (= ventral median precloacal papilla), ventrolateral view; F) Tail of male, lateral view (arrow indicates double papilla); G) Tail tip of male,

lateral view; $\mathrm{H}$ ) Tail tip of female, lateral view. $\mathrm{b}$ - lateral ala; $\mathrm{m}$ - ventromedian organ (= ventral median precloacal papilla); $\mathrm{p}$ - phasmid.

Female (4 nongravid specimens; measurements of allotype in parentheses): Length of body $13.04-21.49$ (18.26) $\mathrm{mm}$, maximum width $367-898$ (612). Lips $122-163$ (163) long. Length of oesophagus $1.92-2.68(2.68) \mathrm{mm}$, representing $14-16(15) \%$ of body length; maximum width $163-245$ (245). Nerve ring and excretory pore $394-544$
(544) and 408 - 571 (571), respectively, from anterior extremity. Ventriculus 122 - 231 x 150-299 (136 x 177); ventricular appendix $952-1,700(1,074) \mathrm{mm}$ long, maximum width 68 - 163 (82). Intestinal caecum 340-490 (490) long, maximum width 95 - 163 (122). Caecum to ventricular appendix length ratio 1:2.2 - 3.8 (1:2.2). Vulva 
pre-equatorial, $5.79-7.41$ (7.41) $\mathrm{mm}$ from anterior end of body, at $41-45$ (41) \% of body length. Vagina directed posteriorly from vulva. Uterus empty. Tail conical, $313-$ 367 (367) long, with pair of lateral papilla-like phasmids (Fig. 1C, 3C,H); tip 30-39 (30) long, bearing numerous spines (Figs 1C, F, 3C, H).

Type host: Giant mottled eel, Anguilla marmorata (Anguillidae, Anguilliformes) (body length 615-1082 mm TL). Site of infection: Stomach (adults) and intestine (larvae).

Type locality: Mngazi River (31 ${ }^{\circ} 37.044^{\prime}$ 'S, $\left.29^{\circ} 25.715^{\prime} \mathrm{E}\right)$, South Africa (collected 30 March - 4 April 2011).

Prevalence and intensity: $30 \%$ (7 fish infected/23 fish examined); 1 - 10 (mean 3) nematodes per fish.

Deposition of specimens: Holotype, allotype and paratypes in the Helminthological Collection of the Institute of Parasitology, Biology Centre of the Academy of Sciences of the Czech Republic, České Budějovice (Cat. No. N-980). Etymology: The specific name of this nematode relates to the genitive form of the generic name of the host.

\section{Discussion}

The gross morphology of the present specimens from $A$. marmorata, particularly the structure of the cephalic end, situation of the excretory pore and presence of both the intestinal caecum and the ventricular appendix, shows clearly their appurtenance to the genus Hysterothylacium. Whereas Bruce et al. (1994) listed 52 species of Hysterothylacium parasitic as adults in marine, estuarine and freshwater fishes, Li et al. (2007a) reported 61 species in this genus, providing a key to their identification. However, 11 congeneric species previously established by Indian authors were not included: $H$. aetobathum Lakshmi, 2005, H. carutti Lakshmi, Rao et Shyamasundari, 1993, $H$. channai Lakshmi, 1995, H. fossillii Lakshmi, 1996, H. japonicum Rajialakshmi, 1996, H. kiranii Lakshmi, 1993, H. longicaecum Lakshmi, Rao et Shyamansundari, 1993, H. narayensis Lakshmi, 1997, H. nellorensis Lakshmi, 1996, H. neocornutum Rajialakshmi, Rao et Shyamasundari, 1992 and H. punctati Lakshmi, 1995 (see Lakshmi, 1993, 1995a,b, 1996a,b, 1997, 2005; Lakshmi, Rao \& Shyamasundari, 1993a,b; Rajialakshmi, 1996; Rajialakshmi, Rao \& Shyamasundari, 1992). Nevertheless, descriptions of these Indian species are poor and, in some cases, their actual generic appurtenance is not clear; therefore, all these species should be considered species inquirendae. The morphology of $H$. japonicum shows that this species belongs to Iheringascaris Pereira, 1935, where it should be transferred as I. japonica (Rajialakshmi, 1996) comb. n. Consequently, Hysterothylacium japonicum Moravec et Nagasawa, 1998 (see Moravec \& Nagasawa, 1998 ) is not its homonym and, therefore, there is no need to re-name this species. Also H. neocornutum should be transferred to Iheringascaris as I. neocornuta (Rajialakshmi, Rao et Shyamasundari, 1992) comb. n.

Later an additional 3 species of Hysterothylacium, $H$. liparis Li, Xu et Zhang, 2007, H. burtti Raffel et Anderson, 2009 and H. spirale Rossin, Datri, Incorvaia \& Timi, 2011, were described (Li et al., 2007b; Raffel \& Anderson, 2009; Rossin et al., 2011), and Li et al. (2008) synonymized Hysterothylacium muraenesoxin (Luo, 1999) with $H$. amoyense (Hsü, 1933). Consequently, at present this genus contains 66 valid species.

Only the following 8 species possess a markedly short caecum and a long ventricular appendix, spicules exceeding $1 \mathrm{~mm}$, and the caudal tip bearing numerous small cuticular denticles as in the new species: $H$. amoyensis Hsü, 1933, H. arnoglossi Petter et Maillard, 1987, H. bifidalatum Petter et Maillard, 1987, H. chaunaxi (Olsen, 1952), H. fabri (Rudolphi, 1819), H. reliquens (Norris et Overstreet, 1975), H. rhacodes Deardorff et Overstreet, 1978 and H. scomberomori (Yamaguti, 1941) (see Deardorff \& Overstreet, 1978, 1980; Petter \& Maillard, 1987; Bruce, 1990; Li et al, 2008). In contrast to the new species, all of them are parasites of marine fishes.

However, $H$. amoyensis differs from the new species in having a highly reduced caecum (reaching at most the level of the anterior end of ventriculus) and in a very different shape of lips; H. arnoglossi in possessing well-developed lateral alae, deep postlabial grooves and a different shape of lips; $H$. bifidalatum in having the ventricular appendage longer than oesophagus, in a different shape of lips and their much narrower bases, bifid lateral alae and spicules representing only $2.4-2.7 \%$ (vs. $5.2-5.8 \%$ ) of the body length; $H$. chaunaxi mainly in the shape and structure of lips (lips widest at base, their flanges not forming marked posterior extensions) and the number of postanal papillae ( 7 vs. 5 pairs); H. fabri in the shape and structure of lips, conspicuously narrow bases of lips, very low interlabia and in the number and arrangement of postanal papillae $(7-9$ vs. 5 pairs); $H$. reliquens in having postanal papillae of the 3rd (vs. 2nd) pair doubled, a lower ratio of the caecal to the ventricular appendage length in male (1:2.2 - 3.5 vs. 1:3.0 - 5.2) and in the shape of lips; $H$. rhacodes in having a conspicuously wrinkled cuticle on the female tail, in the absence of doubled postanal papillae and a ventromedian organ, and in the shape and structure of lips; and $H$. scomberomori in possessing more pairs of postanal papillae (7 - 11 vs. 5), absence of doubled papillae and in a different shape of lips.

According to Mozgovoy (1953), the only Hysterothylacium (reported as Contracaecum) species recorded from freshwater eels (Anguillidae) is H. aduncum aduncum (Rudolphi, 1802), a parasite principally of Clupeiformes, but also of some other fishes in Europe, northern and eastern Asia and Americas, which was found in the European eel Anguilla anguilla (Linnaeus) (Hartwich, 1975; Moravec, 1994). This species differs distinctly from $H$. anguillae sp. n. mainly in having the caecum approximately as long as the ventricular appendix, broad lateral alae and in the shape of lips. Subsequently, Rajyalaksmi et al. (1992) described $H$. neocornutum from the stomach of the freshwater eel Anguilla bicolor bicolor McClelland in India. However, its structure of the cuticle and other features show that this species is a representative of the genus Iheringascaris as redefined by Deardorff \& Overstreet (1980), to which it 
should be transferred (see above). Consequently, the new species is the second species of Hysterothylacium recorded from eels of the family Anguillidae.

In the present study, males, nongravid females and fourthstage larvae but no ovigerous females of $H$. anguillae sp. n. were found in the digestive tract of infected Anguilla marmorata. This suggests that this parasite may exhibit a pronounced seasonal maturation cycle as, for example, the European ascaridoid fish nematode Raphidascaris acus (Bloch, 1779) (see Moravec, 1994).

\section{Acknowledgements}

We thank Dominik Brödlin and Maxwell Barson for assistance during the requiration and dissection of the eels. Thanks are also due to the staff of the Laboratory of Electron Microscopy, Institute of Parasitology, BC ASCR, České Budějovice, for their technical assistance, and to Blanka Škoríková of the same Institute, for her help with illustrations. This study was supported by the National Research Foundation of South Africa (UID: 72088), the Bundesministerium für Bildung und Forschung of Germany, and partly by the Czech Science Foundation grant (P505/12/G112) and the research project of the Institute of Parasitology, BC ASCR (Z60220518). The Department of Economic Affairs, Environment and Tourism, Eastern Cape is thanked for issuing permits to conduct this research.

\section{References}

BRUCE, N. L. (1990): Redescription of the ascaridoid nematode Hysterothylacium scomberomori (Yamaguti) from Australian Spanish mackerel Scomberomorus commerson (Lacepède). Mem. Queensl. Mus., 28: 427 - 434

Bruce, N. L., Adlard, R. D., CANnON, L. R. G. (1994): Synoptic checklist of ascaridoid parasites (Nematoda) from fish hosts. Inver. Taxon., 8: $583-674$

DEARDORFF, T. L., OverstreET, R. M.(1978): Thynnascaris rhacodes sp. n. (Nematoda: Ascaridoidea) in fishes from the Israeli Mediterranean coast. Ann. Parasitol., 53: $519-525$

DEARDORFF, T. L., OVERSTREET, R. M. (1980): Review of Hysterothylacium and Iheringascaris (both previously = Thynnascaris) (Nematoda: Anisakidae) from the northern Gulf of Mexico. Proc. Biol. Soc. Wash., 93: 1035 - 1079

Froese, R., PAuly, D. (Eds) (2011): FishBase. World Wide Web electronic publication, version 10/2011. http://www.fishbase.org

HARTWICH, G. (1975): Schlauchwürmer, Nemathelminthes Rund- oder Fadenwürmer, Nematoda parasitische Rundwürmer von Wirbeltieren I. Rhabditida und Ascaridida. Die Tierwelt Deutschlands 62. Jena, VEB Gustav Fischer Verlag, $256 \mathrm{pp}$.

KHaliL, L. F., Polling, L. (1997): Check list of the helminth parasites of African freshwater fishes. Republic of South Africa, University of the North, $185 \mathrm{pp}$.

LAKSHMI, R. I. (1993): Hysterothylacium kiranii n. sp.
(Nematoda: Anisakidae) from the body cavity of Channa (Ophiocephalus) punctatus. Ind. J. Parasitol., 16: 83

LAKSHMI, R. I. (1995a): Hysterothylacium channai n. sp. (Nematoda: Anisakidae) from the intestine of Channa punctatus (Bloch) from Kolleru lake (Andhra Pradesh). Riv. Parassitol., 12: $221-228$

LAKSHMI, R.I. (1995b): Hysterothylacium punctati sp. nov. (Nematoda: Anisakidae) from the stomach of the freshwater fish, Channa punctatus Bloch. Geobios New Rep., 14: $123-129$

LAKSHMI, R. I. (1996a): Description of new species of Hysterothylacium Ward and Magath, 1917 (Nematoda: Anisakidae) from the intestine of the freshwater catfish Heteropneustes fossilis (Bloch). Riv. Parassitol., 13: 169 - 176 LAKSHMI, R. I. (1996b): Hysterothylacium nellorensis sp. nov. (Nematoda: Anisakidae) from freshwater fish, Labeo bogut (Sykes). Geobios New Rep., 15: 77 - 81

LAKSHMI, R. I. (1997): Hysterothylacium narayanensis n. sp. (Nematoda: Anisakidae) from the body cavity of Barbus ticto (Günther). Uttar Pradesh Zool. Soc., 17: 151 155

LAKSHMI, R. I., RAO, H. K., SHYAMASUNDARI, K. (1993a): Hysterothylacium carutti n. sp. (Nematoda: Anisakidae) from the marine fish Johnius carutta Bloch of Bay of Bengal, Visakhapatnam. Uttar Pradesh J. Zool., 13: 1 - 10 LAKSHMI, R. I., RAO, H. K., SHYAMASUNDARI, K. (1993b): Hysterothylacium longicaecum n. sp. (Nematoda: Anisakidae) from the intestine and stomach of freshwater fishes of Visakhapatnam. J. Parasitol. Appl. Anim. Biol., 2: 1 - 5

LI, L., AN, R., ZHANG, L. (2007a): A new species of Hysterothylacium (Nematoda: Anisakidae) from marine fishes from Yellow Sea, China, with a key to the species of the genus Hysterothylacium. Zootaxa, 1614: 43 - 52

LI, L., XU, Z., ZHANG, L. (2007b): A new species of genus Hysterothylacium Ward et Magath, 1917 (Nematoda, Anisakidae) from Liparis tanakae (Scorpaeniformes, Liparidae) from the Yellow Sea, China. Acta Parasitol., 52: 371 - 375. DOI: 10.2478/s11686-007-0034-Z

LI, L., XU, Z., ZHANG, L. (2008): Redescription of three species of Hysterothylacium (Nematoda: Anisakidae) from marine fishes from the Yellow Sea, China, with the synonymy of Hysterothylacium muraenesoxin (Luo, 1999). Zootaxa, 1878: $55-67$

MORAVEC, F. (1994): Parasitic nematodes of freshwater fishes of Europe. Prague and Dordrecht, Boston, London, Academia and Kluwer Academic Publishers, 473 pp.

MoraVEC, F., NAGASAWA, K. (1998): Hysterothylacium japonicum sp. n. (Nematoda: Anisakidae) from the rare marine fish Trachipterus ishikawai in Japan. Acta Parasitol. $43: 39-42$

MozGovoy, A. A. 1953: [Ascaridata of animals and man and diseases caused by them. Osnovy nematodologii 2.] Moscow, Publ. House of the USSR Acad. Sci., 616 pp. (In Russian.)

OBIeKezIE, A. I., Möller, H., ANDERs, K. (1988): Diseases of the African estuarine catfish Chrisichthys nigrodigitatus (Lacèpéde) from the Cross River Estuary. $J$. Fish Biol., 32: 207 - 221 
Petter, A. J., Cabaret, J., Tcheprakoff, R. (1995): Ascaridoid nematodes of teleostean fishes from the eastern North Atlantic and seas of the north of Europe. Parasite, 2: $217-230$

PetTer, A. J., Maillard, C. (1987): Ascarides des Poissons de Méditerranée occidentale. Bull. Mus. Nat. Hist. Nat., 4 Sér., Sect. A, 9: $773-798$

RAFFEL, T. R., ANDERSON, T. K. (2009): A new species of Hysterothylacium (Nematoda: Anisakidae) from the stomach of the red-spotted newt, Notophthalmus viridescens, from Pennsylvania fishless ponds. J. Parasitol., 95: 1503 1506. DOI: http://dx.doi.org/10.1645/GE-2092.1

RAJYALAKSHMI, I. 1996: Description of a new species of
Hysterothylacium Ward and Magath, 1917 (Nematoda: Anisakidae) from the intestine of marine fish, Nemipterus japonicus (Bloch). Riv. Parassitol., 8: 53 - 60

RaJyalaKshmi, I., RaO, H. K., Shyamasundari, K. (1992): Hysterothylacium neocornutum n. sp. (Nematoda: Anisakidae) from the freshwater fish, Anguilla bicolor bicolor McClelland of Godavari river (Rajahmundry). Riv. Parassitol., 9: 147 - 159

Rossin, M. A., DAtri, L. L., IncorvaiA, I. S., Timi, J. T. (2011): A new species of Hysterothylacium (Ascaridoidea, Anisakidae) parasitic in Zenopsis conchifer (Zeiformes, Zeidae) from Argentinean waters. Acta Parasitol., 56: 310 - 314. DOI: 10.2478/s11686-011-0062-6 